\title{
COVID-19 - A perspective of health care workers at Tertiary Care Hospital in Karachi - A Clinical Survey.
}

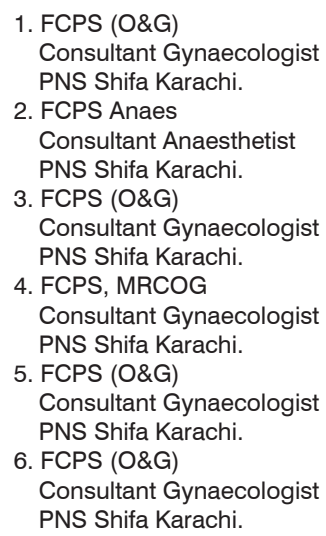

Correspondence Address: Dr. Amera Tariq Department of Gynaecology PNS Shifa Karachi. ameratariq@gmail.com

Article received on: 21/09/2020

Accepted for publication: $24 / 11 / 2020$

\begin{abstract}
Amera Tariq', Tariq Mahmood ${ }^{2}$, Aysha Shahid ${ }^{3}$, Nadia Maqbool ${ }^{4}$, Rabiah Anwar ${ }^{5}$, Afeera Afsheen ${ }^{6}$
ABSTRACT... Objective: To assess the knowledge of healthcare officials about COVID-19 disease and its effects on the mental health of healthcare workers (HCWs). Study Design: Cross sectional Survey. Setting: Tertiary Care Hospital in Karachi. Period: $1^{\text {st }}$ February to $30^{\text {th }}$ June 2020. Material \& Methods: After approval of the hospital's ethical committee, $70 \mathrm{HCWs}$, filled the pre-formed questionnaire including their demographic features, speciality and questions related to fear, stressful factors and strategies to mitigate this stress. Results: A total of 120 questionnaires were distributed to healthcare workers at a peripheral hospital with a return of $58.3 \%$. Majority were females, $59(84.3 \%)$. The mean age was 30.32 years \pm 8.17 SD. All of our participants perceived it their professional and ethical responsibility to perform duties during COVID-19 pandemic. $97.1 \%$ felt proud to be serving humanity. $57.1 \%$ of HCWs were anxious. $52.9 \%$ were satisfied with hospital policies and felt appreciated. Triggering factors for the mental stress included: psychological conflict between profession and personal safety $71.4 \%, 87.1 \%$ feared intubation of colleagues, lack of family support among $38.6 \%, 92.9 \%$ were afraid of transmitting the infection to their families while $88.6 \%$ had anxiety due to uncertainty regarding when the pandemic will end. Various techniques employed by HCWs to cope with this stress included prayers, sports and exercise (95.7\%), self-motivation (88.6\%)and psychologist's help (41.4\%). Conclusion: The COVID-19 pandemic has led to mental stress to HCWs from multiple factors and special attention to strategies to alleviate this stress is strongly recommended.
\end{abstract}

Key words: Anxiety, COVID-19, Healthcare Workers, Mental Stressors, Psychological Effects.

Article Citation: Tariq A, Mahmood T, Shahid A, Maqbool N, Anwar R, Afsheen A. COVID-19 - A perspective of health care workers at Tertiary Care Hospital in Karachi - A Clinical Survey. Professional Med J 2021; 28(2):131-136. https://doi.org/10.29309/TPMJ/2021.28.02.6089

\section{INTRODUCTION}

COVID-19 pandemic appeared in the Wuhan city of China at the end of 2019. The outbreak rapidly involved many countries worldwide, with increasing infectivity . ${ }^{1}$ The etiology was not clear and was treated as pneumonia initially. ${ }^{1}$ The Centre for Disease Control in China named it as Novel Corona Virus Pneumonia. ${ }^{2}$ The Corona Virus targets the respiratory system of humans mainly with later involvement of other organs and widespread damage due to hypoxic injury. ${ }^{3}$ Corona viruses are a large family of viruses, affecting many animals and humans. World Health Organisation (WHO) named the outbreak as Corona Virus Disease 2019, COVID-19. ${ }^{4}$ After the severe acute respiratory syndrome (SARS) epidemic in 2003, the Novel Corona Virus is believed to be the worst pandemic. ${ }^{5}$
COVID-19 infection is not merely a fever, dyspnoea or an ARDS. This is due a virus protein that binds with a haem part of haemoglobin and displaces iron from haemoglobin molecule which no longer carries oxygen due to lack of iron so hypoxic injury to vital organs of the body occurs. This is a new disease affecting masses throughout the world leading to concerns about mental and physical health due to direct patient care. Recovery of healthcare workers from the disease is of paramount importance to carry out their duties. The pandemic has caused a major health and economic crisis worldwide. The associated morbidity and mortality due to COVID -19 has particularly affected individuals above 60 years of age. The first case of COVID -19 was reported in Pakistan in Karachi on $26^{\text {th }}$ February $2020 .{ }^{6}$ Lockdown is helpful to reduce the spread of 
disease and emergence of new cases. Observing public distancing, using face masks and hygienic practices in the public are extremely helpful. HCWs are unfortunately exposed to abundance of new cases daily, long working hours with limited protective gear and unpredictable circumstances. They have physical exertion, low esteem and even breathing difficulty wearing PPE. Many HCWs feel unprepared to deal with the pandemic as it is a new disease and there are uncertainties especially lack of specific treatment. It may be months before the vaccine is available. The fear of getting the disease themselves has led to grave mental stress superadded by concern of transmission to their families. All these factors take a toll on the HCWs. Identification of the HCWs at risk of burn out, suicide and psychological upset is very relevant. Equally important is to identify the factors provoking this stress to attempt reducing its effect.

According to Government of Pakistan, after the diagnosis of first case in Sindh, the virus gradually spread to other provinces and cities of the country. The confirmed cases of COVID-19 increased rapidly thereafter. ${ }^{6}$ According to $\mathrm{WHO}$, so far more than 7 million cases are infected worldwide (dated 14 June 2020) with 433,000 deaths and more than 4 million patients have recovered. In Pakistan alone, 139,000 people are infected with more than 2600 deaths while 51,000 people have recovered.

Studies on the impact of pandemic on mental health of HCWs during COVID-19 are restricted. Few research articles have addressed mental effects of novel corona virus in Pakistan so far. ${ }^{6}$ The healthcare workers are not well prepared for a new disease. The study encompassed how healthcare workers responded to this outbreak and the measures adopted by them to reduce this stress. This survey was aimed for health care workers (HCWs) of a tertiary care hospital in Karachi, to assess their knowledge and perspective of COVID-19 and their response to the disease under stressful condition. It was designed to determine the psychological effects of the outbreak on the health care workers, factors causing it and the strategies adopted to alleviate the stress.

\section{MATERIAL \& METHODS}

This was a cross-sectional survey carried at a Tertiary care Hospital in Karachi during $1^{\text {st }}$ February-30 $0^{\text {th }}$ June 2020. After the approval of the hospital's ethical committee, (ERC/2020/ GYNAE/15) a predesigned questionnaire was circulated among the HCWs willing to participate in the survey. World Health Organisation sample size calculator was used to calculate a sample size of 110 participants; $92.2 \% .^{7}$ The sample of 15 participant HCWs validated our questionnaire and after approval by concerned specialist, questionnaire was finalised. It consisted of questions about demographic features including age, gender and field of the concerned health care workers and 18 questions encompassing the psychological effect of pandemic on HCWs, causative factors of their anxiety and stress and the strategies employed by them to cope with this stress. Eventually questionnaires were distributed to $120 \mathrm{HCWs}$ at a peripheral hospital. Our outcomes were the frequency of mental stressors and the various techniques adopted for these stresses. The data was analysed using SPSS version 20. Quantitative data was presented as mean \pm SD. Qualitative data as frequency and percentage. A total of 70 volunteers were included in this survey. These included consultants of various specialties, residents, medical officers, house officers, paramedical staff, operation theatre assistants as well as medical students.

\section{RESULTS}

A total of 70 participants filled our questionnaire. The mean age was 30.32 years $\pm 8.17 \mathrm{SD}$. Majority $59(84.3 \%)$ were females. The job description is shown in Figure-1.

The psychological effect of Novel Corona Virus on the Health Care Workers is shown in Table-I,II.

The various techniques being employed by health care workers to cope with psychological effects during COVID-19 pandemic is shown in Figure-2. 


\begin{tabular}{|c|c|c|}
\hline Question & Yes & No \\
\hline $\begin{array}{l}\text { Do you feel that it's your professional and ethical responsibility to perform duties } \\
\text { during pandemic? }\end{array}$ & $70(100 \%)$ & - \\
\hline Do you feel nervous and scared during prevalent pandemic? & $40(57.1 \%)$ & $30(42.9 \%)$ \\
\hline Do you want to quit your job due to the associated anxiety? & $16(22.9 \%)$ & $54(77.1 \%)$ \\
\hline $\begin{array}{l}\text { Do you feel appreciated for doing your job during pandemic by the hospital } \\
\text { administration? }\end{array}$ & $37(52.9 \%)$ & $33(47.1 \%)$ \\
\hline $\begin{array}{l}\text { Do you think that you want to continue working but don't want to deal directly with } \\
\text { COVID-19 patients? }\end{array}$ & $43(61.4 \%)$ & $27(38.6 \%)$ \\
\hline Due to feel proud to be serving the humanity during pandemic? & $68(97.1 \%)$ & $2(2.9 \%)$ \\
\hline $\begin{array}{l}\text { Would you prefer to sacrifice your life rather than quitting your job during this } \\
\text { pandemic? }\end{array}$ & $38\left(54.3^{\wedge}\right)$ & $32(46.7 \%)$ \\
\hline $\begin{array}{l}\text { Are you satisfied with the policies of your hospital administration during the COVID-19 } \\
\text { pandemic? }\end{array}$ & $37(52.9 \%)$ & $33(47.1 \%)$ \\
\hline $\begin{array}{l}\text { Do you feel that your relatives are avoiding you because of your being a healthcare } \\
\text { worker? }\end{array}$ & $28(40 \%)$ & $42(60 \%)$ \\
\hline
\end{tabular}

Table-I. Psychological effect of novel corona virus on health care personnel.

\begin{tabular}{|l|c|c|}
\hline \multicolumn{1}{|c|}{ Question } & Yes & No \\
\hline No support from family or appreciation from general public for your services & $27(38.6 \%)$ & $43(61.4 \%)$ \\
\hline Psychological conflict between profession and personal safety & $50(71.4 \%)$ & $20(28.6 \%)$ \\
\hline Fear of seeing colleagues getting intubated & $61(87.1 \%)$ & $9(12.9 \%)$ \\
\hline Fear of transmitting infection to your family and friends & $65(92.9 \%)$ & $5(7.1 \%)$ \\
\hline Fear of your small mistakes / laps in concentration could affect you or others & $67(95.7 \%)$ & $2(2.9 \%)$ \\
\hline Fear of taking care of your own colleagues affected with COVID-19 & $54(77.1 \%)$ & $16(22.9 \%)$ \\
\hline Anxiety due to increased mortality in hospital & $59(84.3 \%)$ & $11(15.7 \%)$ \\
\hline Anxiety due to not knowing when the outbreak will be under control & $62(88.6 \%)$ & $8(11.4 \%)$ \\
\hline
\end{tabular}

Table-II. Aspects of healthcare services that trigger anxiety or stress in health care workers

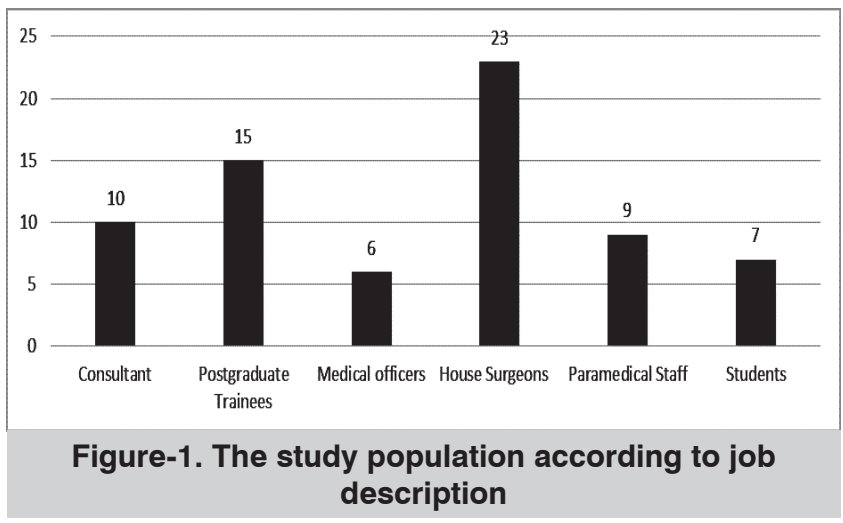

\section{DISCUSSION}

Health Care Workers are facing substantial mental stress as a result of the pandemic. Multiple causative factors have led to initiation of anxiety due to providing direct patient care, increasing burden of seriously ill new cases daily and associated complications. The adverse outcomes associated with this infection are

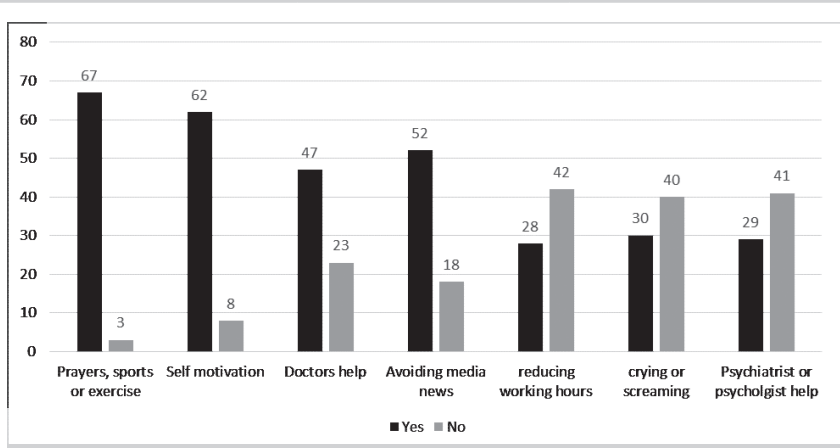

Figure-2. Measures to cope with psychological effects of pandemic.

alarming especially in patients more than 60 years of age having other medical problems. Pakistan's health system is fighting with pandemic for more than 5 months with greater load on the health care resources. HCWs have been facing the challenges of shortages of staff, funds, equipment, and lack of awareness about the disease and uncertainty of the treatment. 
The deleterious effects of pandemic is not only concerning for them but their main fear is the risk of transmission of the disease to their families. ${ }^{8-11}$

Our study showed 40 (57.1\%) of HCWs were nervous and scared of the pandemic while Temsah $\mathrm{MH}$ et al reported $41.1 \% \mathrm{HCW}$ s were worried about COVID-19 pandemic. ${ }^{8-9}$ This study revealed transmitting the infection to family and friends as the main fear ${ }^{8}(2.71 / 5)$, while our study showed $92.9 \%$ of the HCWs were worried about transmission of the disease to their relatives and friends during the pandemic. In a study by Sandesh R, et al. $89 \%$ of health care professionals were afraid of transmitting the disease to their families. ${ }^{12}$ The survey disclosed 16 (22.9\%) of HCWs wanted to quit their jobs due to anxiety. $84.3 \%$ had anxiety due to increased mortality in the hospital.

There is more frequency of depression, anxiety, insomnia and distress in HCWs (41.5\%) caring directly for the patients. ${ }^{10-11}$ This survey disclosed $88.6 \%$ of HCWs were anxious about when the pandemic will end.

The fear of taking infection home and not having rapid access to testing, being isolated and inadequately supported by the health system are other risk factors. ${ }^{10} \mathrm{~A}$ study by Naushad VA et.al ,emphasized poor social support framework could adversely affect mental health. ${ }^{13}$ The Cognitive Behaviour Therapy paradigm reinforces building resilience. ${ }^{14}$ Resilience stems from remaining optimistic and steadfast in difficult situations. Effective communication and adequate training in worst situations could enhance the coping mechanisms.

This survey showed that $37(52.9 \%)$ felt appreciated by the hospital administration while 68(97.1\%) felt proud to be serving humanity. Various measures to deal with psychological effects of outbreak are: engagement in prayers, sports and exercise, self-motivation, avoiding social media, engaging in family affairs, reducing working hours and psychiatrist help.

Social and Psychiatrist support involving confidential telephone lines and drop-in centers could be beneficial in the era of pandemic. ${ }^{15}$ This technique was found to be of great help during the outbreak of SARS. ${ }^{15}$

Promoting peer relations and social support groups could help in promoting mental health services. Recognition of risk factors could help HCWs to meet the field challenges and avoid adverse behaviours. ${ }^{16-18}$ Blake $\mathrm{H}$ et al. developed a digital learning package in UK outbreak of Novel Corona Virus. ${ }^{19}$ It included public involvement, review and evaluation tools. The UK healthcare workers found it to be helpful for their needs in the era of pandemic.

\section{CONCLUSION}

COVID-19 pandemic has led to mental stress to HCWs with uncertainty about their health and concerns due to limited knowledge and lack of treatment modalities so far.

\section{RECOMMENDATIONS}

Effective communication skills are essential to deal with uncertainties pertaining to the pandemic with strong health care system. It includes building and strengthening of coping mechanisms and resilience. The need for special consideration to HCWs, provision of adequate facilities and establishment of online support services and groups can't be over emphasised. Strategies to alleviate this stress should be improved and implemented. The optimal support of HCWs with preventive measures is of utmost importance during this pandemic. This will ensure their protection from the virus and reduce the possibility of them contracting the disease and in turn, alleviate their stress.

\section{Copyright@ 24 Nov, 2020.}

\section{REFERENCES}

1. Sahin AR, Erdogan A, Mutlu Agaoglu P, Dineri Y, Cakirci AY, Senel ME, et al. 2019 Novel Coronavirus (COVID-19) Outbreak: A review of the current literature. EJMO 2020; 4(1):1-7.

2. Wang LS, Wang YR, Ye DW, Liu Q. A review of 2019 Novel Coronavirus (COVID-19) based on current evidence. Int J Antimicrob Agents. 2020:105948. 
3. Hoehl S, Rabenau H, Berger A, Kortenbusch M, Cinatl J, Bojkova D, Neumann P. Evidence of SARS-CoV-2 infection in returning travellers from Wuhan, China. N Engl J Med 2020; 382:1278-1280 DOI: 10.1056/ NEJMc2001899.

4. Alfonso J. Rodriguez-Morales, D. Katterine BonillaAldana, Ruchi Tiwari, Ranjit Sah, Ali A. Rabaan, Kuldeep Dhama, COVID-19, an Emerging Coronavirus Infection: Current Scenario and Recent Developments - An Overview, J. Pure Appl. Microbiol.,2020; 14(1).

5. Wang C, Pan R, Wan X, et all. Immediate psychological responses and associated factors during the initial stage of the 2019 coronavirus (COVID-19) epidemic among the general population in China. Int $\mathrm{J}$ Environ Res Public Health. 2020; 17,p.1729.

6. Abid K, Bari YA, Younas M, Tahir S, Imran A. Progress of COVID-19 epidemic in Pakistan. Asia Pac J Public health. 2020; 4,p.154-156,10.1177/101053952092725.

7. Sandesh R, Shahid W, Dev K, Mandhan N, Shankar P, Sheikh A, etal. Impact of COVID-19 on the Mental Health of Healthcare Professionals in Pakistan. Cureus. 2020; 12(7):e8974. Published 2020 Jul 2. doi:10.7759/ cureus.897. Available at: https://www.ncbi.nlm.nih.gov/ pmc/articles/PMC7402435/ (Accessed on: 8 Sept 2020).

8. Temsah $\mathrm{MH}$, Al-Sohime F, Alamro N, Al-Eyadhy A, AlHasan K, Jamal A, Al-Maglouth I, Aljamaan F, Al Amri M, Barry M, Al-Subaie S, Somily AM. The psychological impact of COVID-19 pandemic on health care workers in a MERS-CoV endemic country. J Infect Public Health. 2020 Jun;13(6):877-882. doi: 10.1016/j. jiph.2020.05.021. Epub 2020 May 29. Erratum in: J Infect Public Health. 2020 Oct;13(10):1599. PMID: 32505461; PMCID: PMC7256548.

9. Shi L, Lu Z, Que J, et al. Prevalence of and risk factors associated with mental health symptoms among the general population in china during the coronavirus disease 2019 pandemic. JAMA Netw Open. 2020; 3(7):e2014053. doi:10.1001/ jamanetworkopen.2020.14053.

10. Wu PE, Styra R, and Gold WL. Mitigating the psychological effects of COVID-19 on health care workers. Canadian Medical Association Journal 2020; 192(17), E459 LP-E460. https://doi.org/10.1503/ cmaj.200519.
11. Lai J, Ma S, Wang Y, Cai Z, Hu J, Wei N,Hu, S. Factors associated with mental health outcomes among health care workers exposed to coronavirus disease 2019. JAMA Network Open,2020; 3(3), e203976-e203976. https://doi.org/10.1001/jamanetworkopen.2020.3976.

12. Sandesh R, Shahid W, Dev K, et al. Impact of COVID 19 on the Mental Health of Healthcare Professionals in Pakistan. Cureus 2020; 12 (7):e8974. doi: 10.7759/ cureus.8974.

13. Naushad VA,Bierens JJ, Nishan KP, et all A systematic review of the impact of disaster on the mental health of medical responders. Prehospital Disasater Med,2019; 34,p.632-643.

14. Padesky CA, Mooney KA. Strengths-based cognitive behavioral therapy: A four step model to build resilience. Clin Psychol Psychother,2012:19,p.283-290.

15. Maunder R, Hunter, J, Vincent L, Bennett J, Peladeau $\mathrm{N}$, Leszcz M, Mazzulli T. The immediate psychological and occupational impact of the 2003 SARS outbreak in a teaching hospital. Canadian Medical Association Journal 2003; 168(10), 1245 LP - 1251. Retrieved from http://www.cmaj.ca/content/168/10/1245.abstract.

16. Kang L, Li Y, Hu S, Chen M, Yang C, Yang B, Liu Z. The mental health of medical workers in Wuhan, China dealing with the 2019 novel coronavirus. The Lancet Psychiatry 2020; 7(3), e14. https://doi.org/10.1016/ S2215-0366(20)30047-X.

17. Brooks SK, Webster RK, Smith LE, Woodland L, Wessely S, Greenberg N, Rubin GJ. The psychological impact of quarantine and how to reduce it: rapid review of the evidence. Lancet. 2020 Mar 14;395(10227):912920. doi: 10.1016/S0140-6736(20)30460-8. Epub 2020 Feb 26. PMID: 32112714; PMCID: PMC7158942.

18. El-Hage W, Hingray C, Lemogne $C$, et al. Les professionnels de santé face à la pandémie de la maladie à coronavirus (COVID-19): Quels risques pour leur santé mentale [Health professionals facing the coronavirus disease 2019 (COVID-19) pandemic: What are the mental health risks?]. Encephale. 2020; 46(3S):S73-S80. doi:10.1016/j.encep.2020.04.00.

19. Blake H, Bermingham F, Johnson G, Tabner A. Mitigating the psychological impact of COVID-19 on healthcare workers: a digital learning package. International Journal of Environmental Research and Public Health. 2020 Jan;17(9):2997. doi:10.3390/ijerph17092997. 


\begin{tabular}{|c|l|l|l|}
\hline \multicolumn{3}{|c|}{ AUTHORSHIP AND CONTRIBUTION DECLARATION } \\
\hline Sr. \# & Author(s) Full Name & \multicolumn{1}{|c|}{ Contribution to the paper } & Author(s) Signature \\
\hline 1 & Amera Tariq & Main conception \& research. \\
2 & Tariq Mahmood & Research and data analysis. \\
3 & Aysha Shahid & Facilitation. & \\
4 & Nadia Maqbool & Facilitation. & \\
5 & Rabiah Anwar & Facilitation. & \\
6 & Afeera Afsheen & Facilitation. \\
\hline
\end{tabular}

